Review Article

\title{
Desmoplastic Small Round Blue Cell Tumor: A Review of Treatment and Potential Therapeutic Genomic Alterations
}

\author{
Ajaz Bulbul, ${ }^{1,2}$ Bridget Noel Fahy, ${ }^{3}$ Joanne Xiu, ${ }^{4}$ Sadaf Rashad, ${ }^{5}$ Asrar Mustafa, ${ }^{6}$ \\ Hatim Husain, ${ }^{7}$ and Andrea Hayes-Jordan ${ }^{8}$ \\ ${ }^{1}$ Department of Hematology/Oncology, Kymera Independent Physicians, Carlsbad, NM, USA \\ ${ }^{2}$ Division of Internal Medicine, Department of Hematology/Oncology, Texas Tech University Health Sciences Center School \\ of Medicine, Lubbock, TX, USA \\ ${ }^{3}$ Department of Surgery, University of New Mexico, Albuquerque, NM, USA \\ ${ }^{4}$ Caris Life Sciences, Phoenix, AZ, USA \\ ${ }^{5}$ All Saints University School of Medicine, Roseau, Dominica \\ ${ }^{6}$ Acharya Shri Chander College of Medical Sciences and Hospital, Jammu, India \\ ${ }^{7}$ Moores Cancer Center, University of California, San Diego, La Jolla, CA, USA \\ ${ }^{8}$ Department of Pediatric Surgical Oncology, University of Texas MD Anderson Cancer Center, Houston, TX, USA
}

Correspondence should be addressed to Ajaz Bulbul; ajazbulbul@gmail.com

Received 9 June 2017; Accepted 17 September 2017; Published 1 November 2017

Academic Editor: Chandrajit Premanand Raut

Copyright $\odot 2017$ Ajaz Bulbul et al. This is an open access article distributed under the Creative Commons Attribution License, which permits unrestricted use, distribution, and reproduction in any medium, provided the original work is properly cited.

\begin{abstract}
Desmoplastic small round blue cell tumors (DSRCTs) originate from a cell with multilineage potential. A molecular hallmark of DSRCT is the EWS-WT1 reciprocal translocation. Ewing sarcoma and DSRCT are treated similarly due to similar oncogene activation pathways, and DSRCT has been represented in very limited numbers in sarcoma studies. Despite aggressive therapy, median survival ranges from 17 to 25 months, and 5-year survival rates remain around 15\%, with higher survival reported among those undergoing removal of at least $90 \%$ of tumor in the absence of extraperitoneal metastasis. Almost $100 \%$ of these tumors contain $\mathrm{t}(11 ; 22)$ (p13;q12) translocation, and it is likely that EWS-WT1 functions as a transcription factor possibly through WT1 targets. While there is no standard protocol for this aggressive disease, treatment usually includes the neoadjuvant HD P6 regimen (high-dose cyclophosphamide, doxorubicin, and vincristine (HD-CAV) alternating with ifosfamide and etoposide (IE) chemotherapy combined with aggressively attempted R0 resection). We aimed to review the molecular characteristics of DSRCTs to explore therapeutic opportunities for this extremely rare and aggressive cancer type.
\end{abstract}

\section{Background}

Desmoplastic small round blue cell tumors (DSRCTs) are a highly aggressive and rare mesenchymal tumor, of which approximately $200-450$ cases have been described so far $[1,2]$. DSRCT was first reported as a separate identity in 1989 by Gerald and Rosai [3] who proposed that DSRCT arose during development from a progenitor cell with potential for multiphenotypic differentiation [4].

\section{Clinical Presentation}

Young men comprise the vast majority of cases with a mean age at diagnosis of 22 years $[2,5,6]$. Clinically, DSRCT has been shown to have a predilection for developing in the abdominal and pelvic cavity with extra-abdominal involvement being much less common [5].

In the majority of cases, patients with DSRCT present with advanced disease. Most patients remain asymptomatic for extended periods of time, and diagnosis is made when tumor burden is significant [2]. The most common symptoms are abdominal pain and weight loss [5]. Constipation due to mass effect caused by the tumor and bowel obstruction have also been reported [2]. Due to a significant burden of peritoneal disease, some patients will present with an abdominal mass alone, but the most common presentation is abdominal distension from ascites. Liver metastases are seen both at the time of diagnosis and with 
relapse. Other distant sites include lymph nodes, lungs, and bones $[2,7,8]$. Omental and hepatic metastases can also be seen.

\section{Histopathology}

Histologically, the tumors consist of solid sheets, large nests, small clumps, or cords of cohesive, small, round, ovoid, or spindled cells lying in a hypocellular, desmoplastic, collagenous stroma [5]. Immunohistochemical staining demonstrates the divergent differentiation of the neoplastic cells. Neoplastic cells typically express epithelial (keratin and epithelial membrane antigen (EMA)), mesenchymal (vimentin), neural (CD56 and neuron-specific enolase (NSE)), and muscle (desmin) markers $[4,9]$. The molecular hallmark of DSRCT is the EWS-WT1 fusion protein. The $\mathrm{t}(11 ; 22)$ (p13;q12) translocation is present in virtually all cases [10-12]. The WT1 protein is a transcriptional activator of genes involved in renal and gonadal differentiation; it regulates the mesenchymal to epithelial transition that occurs in renal development. Most of these tumors contain $\mathrm{t}(11 ; 22)$ (p13;q12) translocation, and it is possible that EWS-WT1 functions as a transcription factor, possibly through WT1 targets $[13,14]$.

\section{Diagnostic Studies}

CT scan with oral and intravenous contrast is the imaging modality of choice when evaluating patients with known or suspected DSRCT. Characteristic findings in DSRCT include soft tissue masses which are often bulky (mean, $6 \mathrm{~cm}$; range, $1-28 \mathrm{~cm}$ ), lobulated, and heterogeneous with hypodense areas; these findings are present in up to three-quarters of patients [15], and a significant desmoplastic reaction differentiates DSRCTs from other small round cell tumors [16]. Adenopathies are present in approximately half of patients at the time of diagnosis (intraperitoneal, retroperitoneal, and pelvic) $[15,17]$. In a radiological review of 13 cases of abdominal DSRCT, the most common finding was the presence of several lobulated peritoneal soft tissue masses (mean number of masses/patient $=4$ ). The main sites of peritoneal involvement were the pelvis, omentum, retroperitoneum, and small bowel mesentery. In six cases, moderate ascites was seen. Five of 13 patients had liver metastases, with an average of four lesions per case. Associated thoracic metastases were found in three patients [18].

MRI findings include heterogeneous T1 low signal and heterogeneous T2 high signal. After gadolinium administration, there is heterogeneous contrast enhancement. Subtle hypointense foci are sometimes seen on T2-weighted images representing desmoplastic reaction. Hyperintense T1 signal and fluid/fluid levels may suggest recent hemorrhage in a tumor [19].

FDG-PET scanning has been shown to impart important additional information and has a relevant impact on treatment planning when used in concert with CT scan [20, 21]. FDG-PET is sometimes obtained at diagnosis and during surveillance. FDG-PET/CT has been found to be superior to CT in detection of lymph node involvement (sensitivity, 95\% versus 25\%, resp.), bone lesions (sensitivity,
$90 \%$ versus $57 \%$, resp.), and renal lesions [20]. In a study of 65 patients, FDG uptake was seen in all primary intraabdominal and pelvic tumors [22] and accurately detected $97 \%$ of all DSRCT lesions with sensitivity, specificity, positive, and negative predictive values of $96 \%, 99 \%, 98 \%$, and $97 \%$, respectively. However, CT is more reliable than FDGPET in depicting lung metastases [20].

Core biopsy specimens are preferred to acquire sufficient sample. Fine-needle aspiration specimens, although commonly employed, are not adequate during the workup of DSRCT due to issues with low cellularity of the sample, necrosis, and predominantly a desmoplastic reaction. Fineneedle aspiration is challenging and requires pathological expertise in the utilization of ancillary techniques such as immunocytochemistry and flow cytometric immunophenotyping. The absence of the characteristic desmoplastic stroma in DSRCT and its cytologic features make cytologic interpretation difficult [23]. Characteristic cytologic features are seen in the right clinical context of small round blue cells with cytoplasmic densities and purple-stained connective stroma [24] and should raise suspicion of DSRCT that should be confirmed by its unique cytogenetic abnormality. The cells include granular chromatin and smooth to irregular nuclear membranes and show nuclear molding, cytoplasmic vacuoles, pseudorosettes, and metachromatic stroma [25] compared to other potential diagnoses like Ewing sarcoma. RT-PCR for EWS-WT1 transcript detection is a way of increasing diagnostic accuracy [26]. However, using a combination of both techniques, $86.4 \%$ of DSRCT can be typed accurately $[26,27]$.

\section{Staging}

The UICC staging of sarcoma is inadequate for DSRCT as it classifies nearly all patients as metastatic [2]. Several staging methods have been proposed for DSRCT, and there is currently no validated staging system. Due to the extensive nature of the peritoneal disease frequently present, the Peritoneal Cancer Index is often used. In this system, the abdominal cavity is divided into 13 regions, and each region is assigned a lesion size score ranging from 0 (no tumor seen) to 3 (tumor $>5 \mathrm{~cm}$ or confluence) [28]. The MD Anderson group has suggested the inclusion of liver and extraabdominal metastases into this staging system to adjust for the use of hyperthermic intraperitoneal chemotherapy (HIPEC) and the finding that extra-abdominal metastasis correlated with poor survival [29]. It is unclear if this strategy applies to the adult population since the median age in that study was 12 years in few who underwent HIPEC. The estimated median overall 3-year survival for patients not undergoing surgery or HIPEC was $26 \%$ compared with $71 \%$ in patients who underwent HIPEC and surgery compared with $62 \%$ who only received debulking surgery [7].

\section{Imaging}

CT scan with contrast is the imaging of choice for staging and surveillance. CT is more reliable than FDG-PET in depicting lung metastases [20]. Soft tissue masses seen are often bulky 
(mean, $6 \mathrm{~cm}$; range, 1-28 cm), lobulated, and heterogeneous with hypodense areas up to three-quarters of patients. Adenopathy is present in about half the time of the diagnosis (intraperitoneal, retroperitoneal, and pelvic). Occasionally, moderate ascites is seen [18]. FDG-PET scanning has been shown to impart important additional information and has a relevant impact on changing treatment planning when used in concert with CT scan $[20,30]$. FDG-PET can be used at diagnosis and during surveillance and has been found to be superior to $\mathrm{CT}$ in detection of lymph node involvement (sensitivity, 95\% versus 25\%, resp.) and bone metastases (sensitivity, 90\% versus 57\%, resp.) [20].

\section{Molecular Findings}

As in certain other tumors, the function of the Wilms tumor protein (WT1) in repressing gene transcription is lost in DSRCT [31]. There is reported loss of the zinc finger region of WT1 in EWS-WT1 which serves to convert WT1 from a repressor of transcription to a dominant transcriptional activator oncogene including some 35 target genes [14, 32]. Some of these are growth factor genes such as $P D G F \alpha$; growth factor receptor genes such as IGF-1 receptor, EGFR, and $I L-2 / 15 R \beta[13,33]$; transcriptional regulators including c-MYC, n-MYC, PAX2-2, ENT4, and WT-1; and extracellular protein-encoding genes such as e-Syndecan, E-cadherin, and TALLA-1 which is a tetraspanin-family genes that encodes transmembrane proteins responsible for regulating cell adhesion, migration, and metastasis [34]. CCN2 (connective tissue growth factor) is highly expressed in DSRCT and may have autocrine or paracrine roles in disease progression [31]; however, the precise contribution of these molecular events and their potential as a therapeutic target remain poorly understood and applied.

Embryologically, WT1 is involved in urogenital development [35]. Normal WT1 protein is expressed in tissues which undergo mesenchymal-epithelial conversion from mesoderm [36] and may have a role in mesothelial formation in embryonic development [37]. This may explain the mesenchymal propensity of the tumor and some usage of the name "mesothelioblastoma." Variant fusion isoforms generated due to alternative mRNA splicing have led to discovery of two protein isoforms. Some of these cases express full-length WT1 or have variant transcripts (KTS+), resulting in atypical staining patterns. The KTS+ variant has different transcriptional targets than the KTS- isoform [38].

Neither isoform of EWS-WT1 is sufficient to transform wild-type murine embryonic fibroblasts (MEFs). The oncogenic potential of both can be unmasked by $\mathrm{p} 53$ loss as seen by nuclear localization of $\mathrm{p} 53$, and copy-number amplification and gene-set enrichment analysis demonstrated augmentation of the WNT pathway [39]. In the absence of intact p53 protein, WT1 acts as a transcriptional activator [40].

Genomic analysis on LMS, UPS, and MPNST has shown novel genetic alterations; however, DSRCT has been represented in very limited numbers [41]. Limited sequencing studies have been performed on DSRCT because of the small number of cases shown. Protein biomarkers show c-kit in $19 \%$ of cases, and HER2/neu overexpression (3+) is also seen but uncommon in desmoplastic small round cell tumors [42]. EGFR gene amplification occurs at a rate of $16.9 \%$ by FISH. This was also true for LMS, MPNST, osteosarcoma, and UPS [41].

Molecular profiling on 35 DSRCTs sampled from patients having surgery for DSRCT (Caris Life Sciences, Phoenix, AZ) that were compared with Ewing sarcoma revealed low immunogenicity ( $<10$ mutations/Mb) and low frequency of actionable mutations including PD-L1 in both tumor types. High AR expression could present as a potential therapeutic target for DSRCT while taxanes may be more effective in Ewing sarcoma compared to DSRCT based on TUBB3 expression [43]. Given the male predominance of this subset of disease, it is not surprising that, when compared to Ewing sarcoma, no significant difference was seen in protein expressions with the exception of a significantly higher overexpression of AR in DSRCT (59\% versus 3\%, $p=1.7 \mathrm{E}-10)$ and TUBB3 (56\% versus $29 \%, p=0.03$ ) [43].

There is known to be relatively low concordance across platforms and for individual genes or proteins. cKIT overexpression by IHC in one study did not associate with $c K I T$ mutations [41]. This is in contrast to GIST, where more than $80 \%$ of cases carry an activating mutation in the KIT gene and more concordance is seen [44]. There is in fact quite a low frequency of actionable mutations detected in series that looked at genomic alterations which overall included only 9 patients of DSRCT [41].

Given the interest in immunotherapy, currently, most of the interest lies with PD-1 and PD-L1 inhibitors. Previous work has shown that both $\mathrm{PD}-1$ positivity and PD-L1 positivity were independent prognostic indicators of OS and EFS in sarcoma [45]. Intratumoral infiltration of PD-1positive lymphocytes and PD-L1 expression have been seen in $65 \%$ and $58 \%$ of STS, respectively [45]. PD-1 positivity and PD-L1 expression are associated with advanced clinicopathological parameters and presence of distant metastasis, and both PD-1 positivity and PD-L1 positivity are independent prognostic indicators of overall survival (OS) $[45,46]$. Over 150 sarcoma subtypes have been analyzed for PD-L1 tumor expression and the presence of PD-1+ tumorinfiltrating lymphocytes (TILs): up to $65 \%$ of sarcomas expressed PD-L1 which, along with PD-1 TIL positivity, correlates with poorer overall survival and aggressive tumor features [47]. DSRCT, however, is not very well represented in these studies.

We now know that a higher mutational rate is observed in melanoma (median of 13.2 mutations per $\mathrm{Mb}$ ) and in NSCLC, reflecting their high responses to immunotherapy. The median of somatic mutations per $\mathrm{Mb}$ is 10.5 for smokers and 0.6 for nonsmokers, in which mutations are known to be secondary caused by selective pressures such as UV light and tobacco smoke exposure, respectively.

Mutational loads are lower in MSS colorectal tumors (3.2 mutations per $\mathrm{Mb}$ ), with higher mutational loads in MSIhigh tumors [48] reflecting their response to PD-1 inhibitors [49]. Low mutational loads of 1.53 mutations per $\mathrm{Mb}$ in RCC may reflect why PD-1 staining was not suggestive of activity to nivolumab [50]. Cytokine-based immunotherapies have also shown limited benefit in the advanced setting 
of sarcomas. A large randomized trial of adjuvant interferon maintenance in resected osteosarcoma patients did not provide significant improvement [51]. DSRCT is not a very immunogenic tumor. Some soft tissue and bone sarcomas have been shown to express PD-1 ligand, and additional information is emerging about the role of somatic mutations in predicting response $[46,51,52]$.

There is recent evidence showing SLFN11 mRNA transcript and protein levels in DSRCT-1 are comparable to EWS cell lines. Schlafen-11 (SLFN11), a putative biomarker for defective DNA damage repair, and SCRT-1 demonstrated sensitivity to PARPi as single agent or in combination with either the topoisomerase I inhibitor irinotecan or ionizing radiation [53].

\section{Treatment}

Aggressive attempts at $\mathrm{R} 0$ resection have been a cornerstone of any curative intent strategy for DSRCT. HIPEC has been shown to optimize outcomes in single-center retrospective studies for disease in the abdomen [54]. Complete cytoreduction is performed prior to HIPEC using cisplatin. Because of large tumor sizes on clinical presentation and unresectable metastatic disease, surgery is usually preceded by induction of neoadjuvant HD chemotherapy, which is followed by consolidation treatment with either radiation or myeloablative treatment (Table 1) $[6,29,55,56]$.

The surgical goal is to remove $>90 \%$ of the tumor [56], and resection to less than $1.0 \mathrm{~cm}$ tumor size [7]. This mostly requires omentectomy, peritoneal stripping, splenectomy for hilar involvement, and local resection of the diaphragmatic peritoneum $[55,56]$. Microscopic negative margins are difficult to achieve because of the desmoplastic nature of the tumor; therefore consolidative 30 Gy WAP-RT [57]/IMRT [58], HIPEC [29], [ $\left.{ }^{90} \mathrm{Y}\right]$ yttrium microspheres radioembolotherapy [59], myeloablative chemotherapy (rarely used now) $[55,56,60]$, or consolidative chemotherapy has been employed in most of these studies, and relapses occur early without consolidation. R0 resection and HIPEC to sterilize extensive peritoneal metastasis can lead to median survival of up to 63 months [54].

DSRCT is somewhat alkylator sensitive, and response seems to be dose responsive [55]. Doxorubicin is a common thread in the treatment of patients who either achieved longterm survival or had response to a standard consolidative radiotherapy dose of $30 \mathrm{~Gy}$ when delivered by external beam to the whole abdomen and pelvis $[57,58]$. Myeloablative chemotherapy with thiotepa and carboplatin, etoposide followed by autologous bone marrow, or peripheral stem cell rescue has been employed with limited success [56, 61]. Case report of $\left[{ }^{90} \mathrm{Y}\right]$ yttrium microspheres radioembolotherapy leading to a dramatic sustained reduction in the hepatic metastatic load has also been reported [59, 62].

Most of the early case reports in the last 2 decades have used standard dose alkylating agents, Adriamycin-based treatment with less than favorable responses [3, 9, 63]. Irinotecan and temozolomide combination has shown up to $68 \%$ objective response in recurrent Ewing sarcoma during early retrospective studies [64]. Phase II study (TEMIRI) of temozolamide $100-125 \mathrm{mg} / \mathrm{m}^{2} /$ day (days $1-5$ ) and irinotecan $10 \mathrm{mg} / \mathrm{m}^{2} /$ day (days $1-5$ and $8-12$ ) every 3 weeks show responses between $33 \%$ in a familiar tumor histology of medulloblastoma with some of the patients having a desmoplastic variant [65].

Kushner et al. reported 10 patients prospectively that were the first to use high-dose alkylator-based therapy (Table 1) in an alternating 7 courses of chemotherapy regimen in 1996. The P6 regimen consisted of high-dose cyclophosphamide, doxorubicin, and vincristine (HD-CAV) on cycles 1, 2, 3, and 6 given with cyclophosphamide $\left(4200 \mathrm{mg} / \mathrm{m}^{2}\right)$, doxorubicin $\left(75 \mathrm{mg} / \mathrm{m}^{2}\right)$, and vincristine (HD-CAV) alternating with ifosfamide (9 to $12 \mathrm{mg} / \mathrm{m}^{2}$ ) and etoposide (500 to $1000 \mathrm{mg} / \mathrm{m}^{2}$ ) on cycles 4,5 , and 7 . The regimen was chosen due to its prior effectiveness and experience of use in Ewing sarcomas and metastatic neuroblastoma in children and young adults where it was called the "N6" protocol; N likely represents neuroblastoma [66, 67].

A modified $\mathrm{P} 6$ regimen and a modified PAVEP regimen [63, 68] (cyclophosphamide, pirarubicin, etoposide, and cisplatin) have been employed to decrease severe adverse events and to improve the completion rate of chemotherapy. These modified regimens use Cytoxan of $4 \mathrm{~g} / \mathrm{m}^{2}$ and replace Adriamycin with pirarubicin. The modified P6 regimen use higher ifosfamide dose ( $12 \mathrm{~g} / \mathrm{m}^{2}$ divided for five days) instead of $9 \mathrm{~g} / \mathrm{m}^{2}$ in the original $\mathrm{P} 6$ regimen. The addition of irinotecan, topotecan, carboplatin, and cisplatin leads to few months of stable disease at best in selected patients [56, 57].

The insensitivity of the tumor to high-dose chemotherapy may implicate a stem cell hypothesis in DSRCT $[69,70]$. This may reflect on the heterogeneity of the tumor and contribute to the general difficulty in eradicating the tumor. Unlike Ewing sarcoma, the putative CD133+ stem cell has not been identified to date $[69,70]$. Quantitative real-time PCR analysis of putative stem cell maintenance revealed that CD133+ ESFT cells express significantly higher levels [70]. This could certainly explain tumor characteristics and lead to the identification of new targets for more effective therapies [70]. Radiation is more easily tolerated in pediatric patients and may improve local control [57, 58]. Most relapses are intraperitoneal and/or hepatic WAP-RT. Acute toxicities are approximately $80 \%$, and almost a third of patients experience acute hematologic toxicity, with grade 4 thrombocytopenia seen in $76 \%$ of patients. Small bowel obstruction occurred in 7 patients (33\%) after surgery and WAPI [57]. In one study, postoperative WAP-RT was predictive of 3-year overall survival, as were the absence of EPM and complete surgical resection. Heated intraperitoneal chemoinfusion with cisplatin had no impact on overall survival in that analysis [1].

\section{Targeted Agents}

It is unclear if, despite poor long-term outcomes, we should continue treating these patients with HD chemotherapy [2] and prolonged in-patient hospital protocols. A standard Ewing sarcoma alternating VAC/IE protocol with standard alkylator doses (Cytoxan $1200 \mathrm{mg} / \mathrm{m}^{2}$ over $60 \mathrm{~min}$ ) and $1800 \mathrm{mg}$ of ifosfamide per square meter per day for five days [71], given with mesna, could be evaluated since oncogene 


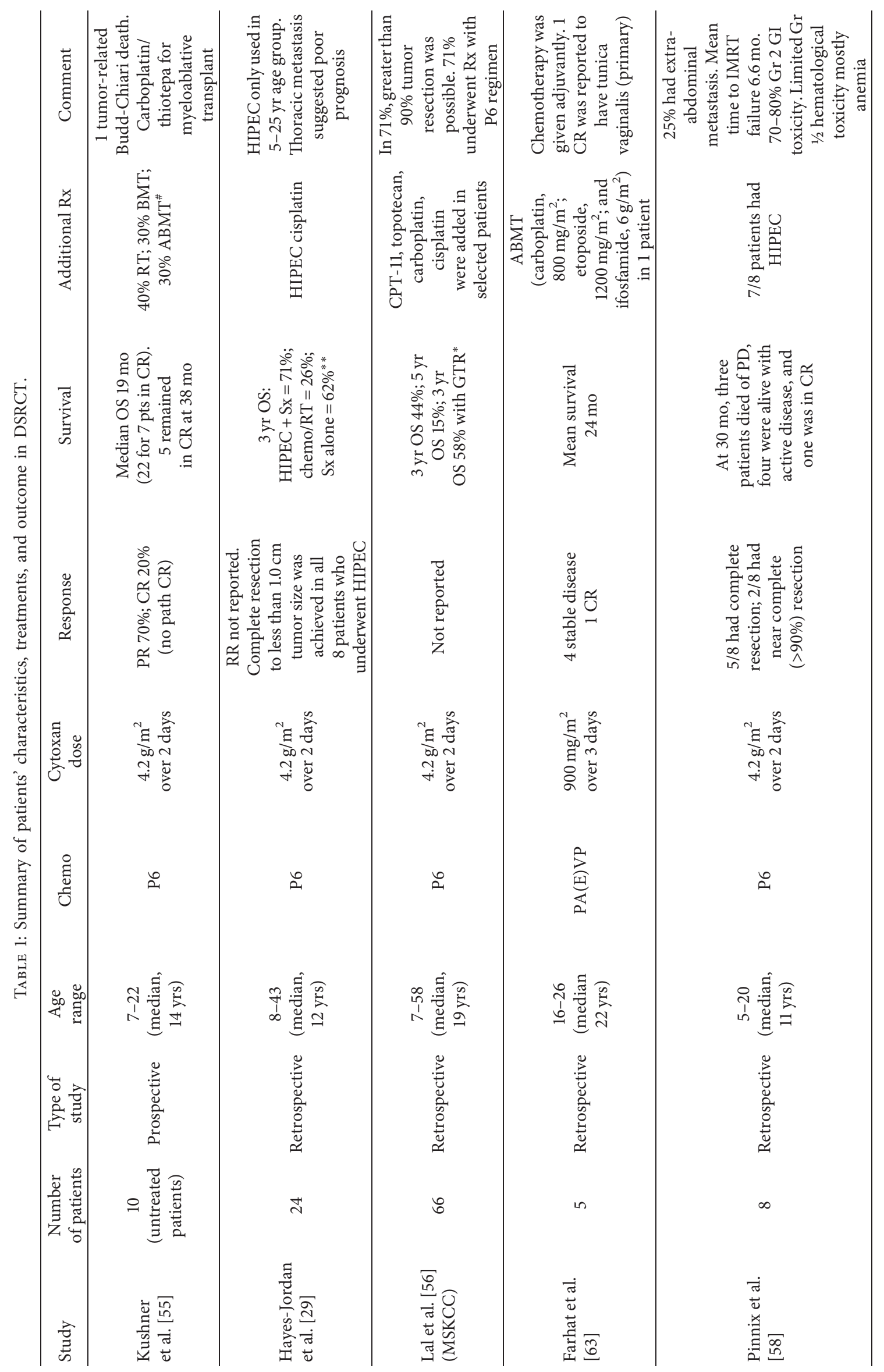




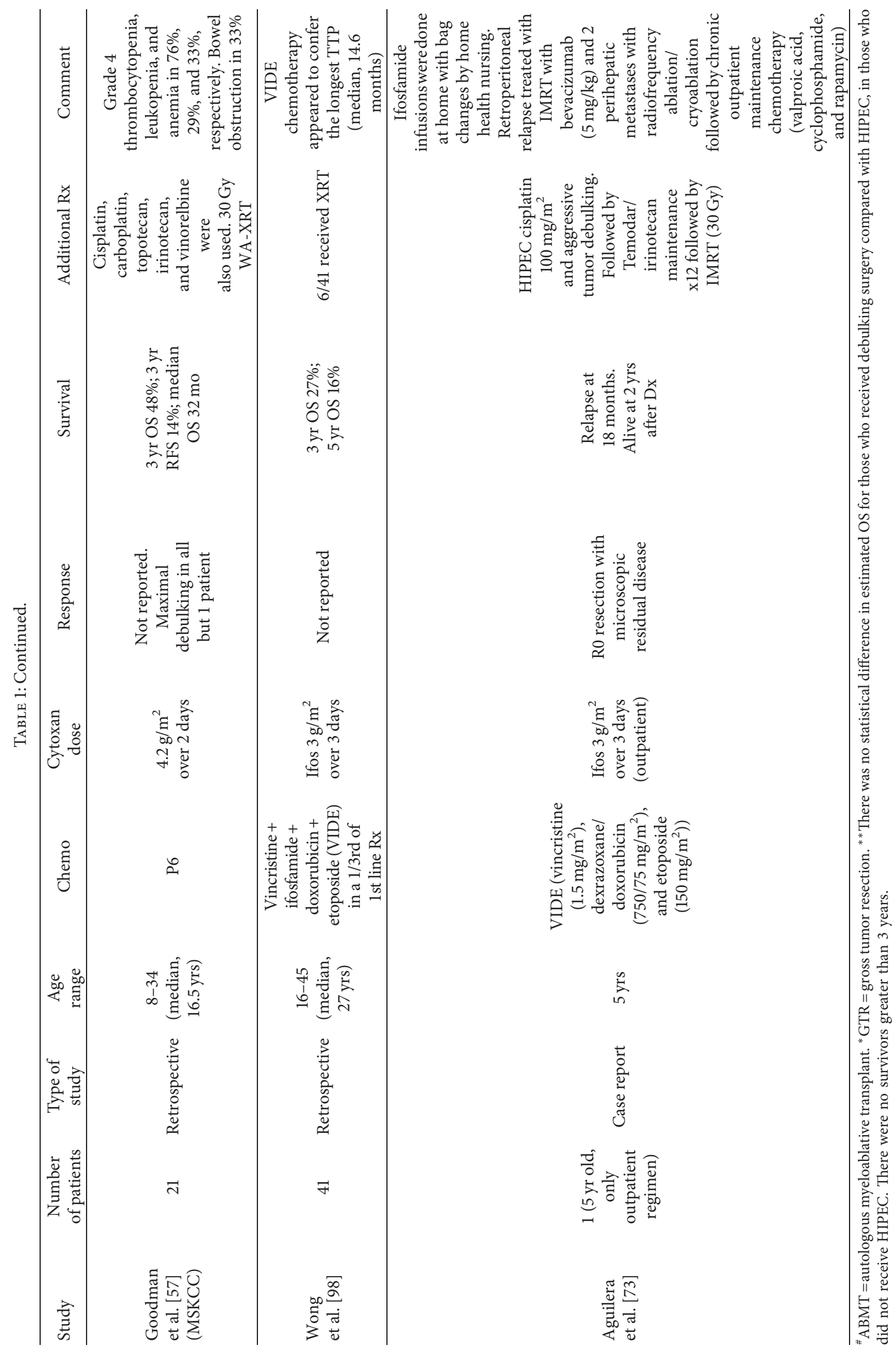


activation pathways in DSRCT may be similar to those in Ewing sarcoma [72]. Some centers are using a modified P6 protocol $[2,68]$ which is similar to $\mathrm{VDC} / \mathrm{IE}$ (vincristine, total dose of $2 \mathrm{mg}$; Adriamycin, $75 \mathrm{mg} / \mathrm{m}^{2}$; and cyclophosphamide, $1200 \mathrm{mg} / \mathrm{m}^{2}$ with mesna). Dactinomycin at $1.25 \mathrm{mg}$ per square meter per dose is substituted for doxorubicin when a total doxorubicin dose of $375 \mathrm{mg}$ per square meter is reached. Ifosfamide and etoposide are administered $\left(1800 \mathrm{mg} / \mathrm{m}^{2}\right.$ of ifosfamide for five days, given with mesna, and $100 \mathrm{mg} / \mathrm{m}^{2}$ of etoposide over five days) [71]. The Ewing sarcoma regimen whether used in a dose-dense or three weekly schedule also provides a maintenance phase of treatment of up to 49 weeks [71]. There is suggestion of longer outcomes with an outpatient maintenance therapy that consisted of irinotecan and temozolomide followed by XRT and HIPEC in a 5-year-old patient [73].

Small molecule TKIs have shown dismal results so far including sorafenib and sunitinib. In a DSRCT cell line, the mTOR inhibitor induces apoptosis [74]; in practice, however, rapamycin and temsirolimus have had limited PFS $[75,76]$. Therefore, mTOR inhibition may only have a role in a combination setting rather than as single therapy. In a retrospective review of patients who received pazopanib within EORTC trials, a clinical benefit rate $(\mathrm{PR}+\mathrm{SD}>12$ weeks) of $78 \%$ was reported among patients who had progressed on prior treatments among 9 patients [77].

Recently, olaratumab, a novel PDGFRa inhibitor, was approved with doxorubicin in soft tissue sarcomas (STS) with a histology subtype for which an anthracycline-containing regimen may be appropriate; however, in the study, DSRCT was not represented [78]. DSRCT had more limited representation with pazopanib approval in the PALETTE trial [79], with eribulin [80], and with the approval of trabectedin [81].

Eribulin has shown activity in pretreated patients with L-sarcomas and recently showed a 2-month survival benefit in the phase III study compared to dacarbazine [80]; however, outcomes in pretreated patients with synovial sarcoma and other types of soft tissue sarcoma did not meet the prespecified primary efficacy endpoint for activity [82]. Ewing family tumors were excluded in the study; however, three-quarters of patients were still alive at 6 months [82], suggesting that microtubule inhibition may warrant further study since vinca alkaloids have historically shown activity with Ewing family tumors [83, 84]. We must perform tumor biomarker evaluations in these clinical trials comparing responding patients with nonresponders to understand who may truly benefit or not from these therapies [83].

Gemcitabine and docetaxel have been used as an outpatient regimen for STS other than leiomyosarcoma and could have benefit in patients unable to tolerate very aggressive chemotherapy [85-87]. A clinical trial undergoing (NCT01532687) is currently looking at gemcitabine with or without pazopanib and is currently recruiting.

IGF-1R inhibition has been seen to mitigate mTOR activation and is supported by preclinical data supporting its additive antitumor effects by combining them [88]. Cixutumumab at $6 \mathrm{mg} / \mathrm{kg}$ IV weekly was combined with temsirolimus in heavily pretreated patients with Ewing family tumors that included DSRCT with one-third of the patients achieving relatively durable CR/PR [89]. This was well tolerated, with preliminary evidence of durable antitumor activity, and attempts to evaluate response in a phase II study for STS after stratifying for the expression of IGF-1R on tumor tissue [90]. Other DSRCT targeted agents include GD2 [91] and ganitumab, a fully human monoclonal antibody against type-1 insulin-like growth factor receptor (IGF-1R), showing 6\% ORR and 17 (49\%) SD rate in an open label phase II trial [92]. These novel clinical trials with biomarker and molecular data-driven interventions reflect the direction this field is moving with the availability of newer diagnostic tools.

\section{Role of Immunotherapy}

Tumor mutational load (TML) may affect response rates to immunotherapy as seen in NSCLC and melanoma. Higher TML tumors are more responsive to immune checkpoint inhibition [52]. Single-agent anti-PD-1 antibodies have had limited efficacy across sarcomas to date. A phase II study (SARC028) is evaluating the role of pembrolizumab across various sarcoma histologies (NCT02301039) [47]. None of the patients in a recently reported DSRCT cohort had identifiable tumoral PD-L1 expression by SP142 antibody testing, and the significance of PD-1-positive TILs is unclear at this time [43]. The composite of tumoral PD-L1 positivity and $\mathrm{PD}-1$ positivity among tumor-infiltrating lymphocytes has been suggested as an indicator of prognosis in soft tissue sarcoma patients [45]. Another small, but heterogeneous, patient cohort at MSKCC demonstrated no association between PD-L1 expression, TIL and clinicopathological features, and overall survival using the DAKO 5H-1 antibody [93]. DSRCT patients, however, were not represented in these small data sets. $\mathrm{B} 7 \mathrm{H} 3$, an immunomodulatory cell surface molecule, is seen in $>90 \%$ DSRCTs. In a phase I study, a radioimmunoconjugate showed promise in an ongoing clinical trial (NCT01099644).

\section{Future Directions}

An ongoing NCT01189643 trial is looking at addition of two cycles of irinotecan, temozolomide, and bevacizumab followed by a standard P6 protocol utilizing the data, suggesting that VEGFR-2 and VEGFA overexpress in DSRCT cell lines and xenograft models [94]. A pilot study evaluating the combination of irinotecan, temozolomide, and bevacizumab is active in patients with DSRCT, and it is feasible to combine these agents with standard chemotherapy without greater than expected toxicity with response rates around 27\% [95].

A phase I/II clinical trial is studying the side effects and the most effective dose of the notch signaling pathway inhibitor RO4929097 when given together with vismodegib in DSRCT patients (NCT01154452). A study looking at intraperitoneal radioimmunotherapy with a novel antibody $8 \mathrm{H} 9$ for patients with DSRCT is also recruiting (NCT01099644).

A current study which is ongoing but not recruiting adds irinotecan, temozolomide, and bevacizumab to the chemotherapy regimen currently used in DSRCT. An ongoing phase II study (SARC028) is looking at the role of pembrolizumab in 
TABLE 2: Clinical trials recently completed in DSRCT.

\begin{tabular}{|c|c|c|c|}
\hline Clinical trial (ID); phase & Drugs & Status & Assigned intervention \\
\hline $\begin{array}{l}\text { NCT01154452; } \\
\text { phase } 1 \mathrm{~B} / \mathrm{II}\end{array}$ & $\begin{array}{c}\text { Vismodegib } \\
\text { (hedgehog inhibitor) and } \\
\text { NOTCH inhibitor RO4929097 }\end{array}$ & Completed & $\begin{array}{c}\text { Vismodegib and Gamma-Secretase/Notch Signalling } \\
\text { Pathway Inhibitor RO4929097 in Treating Patients with } \\
\text { Advanced or Metastatic Sarcoma }\end{array}$ \\
\hline NCT00563680; phase II & Drug: AMG 479 (IGF-R1 Ab) & Completed & $\begin{array}{c}\text { QUILT-3.025: A Phase 2 Study of AMG 479 in Relapsed or } \\
\text { Refractory Ewing's Family Tumor and Desmoplastic } \\
\text { Small Round Cell Tumors }\end{array}$ \\
\hline $\begin{array}{l}\text { NCT00062205; } \\
\text { phase I, II }\end{array}$ & Drug: imatinib mesylate & Completed & $\begin{array}{c}\text { Imatinib Mesylate in Treating Patients With Recurrent } \\
\text { Ewing's Family of Tumors or Desmoplastic Small Round } \\
\text { Cell Tumor }\end{array}$ \\
\hline NCT00055952; phase II & $\begin{array}{l}\text { Drug: exatecan mesylate } \\
\quad \text { (camptothecin) }\end{array}$ & Completed & $\begin{array}{c}\text { Exatecan Mesylate in Treating Patients With Ewing’s } \\
\text { Sarcoma, Primitive Neuroectodermal Tumor, or } \\
\text { Desmoplastic Small Round Cell Tumor }\end{array}$ \\
\hline NCT00720174; phase I & $\begin{array}{l}\text { Biological: cixutumumab } \\
\text { (IGF-1R Ab); drug: doxorubicin } \\
\text { hydrochloride; other: laboratory } \\
\text { biomarker analysis }\end{array}$ & Completed & $\begin{array}{c}\text { Cixutumumab and Doxorubicin Hydrochloride in } \\
\text { Treating Patients With Unresectable, Locally Advanced, } \\
\text { or Metastatic Soft Tissue Sarcoma }\end{array}$ \\
\hline NCT00436657; phase I & $\begin{array}{l}\text { Drug: CHPP of cisplatin; } \\
\text { procedure: abdominal surgery }\end{array}$ & Completed & $\begin{array}{c}\text { Continuous Hyperthermic Peritoneal Perfusion (CHPP) } \\
\text { With Cisplatin for Children With Peritoneal Cancer }\end{array}$ \\
\hline NCT00093821; phase I & $\begin{array}{c}\text { Drug: tanespimycin } \\
\text { (HSP90 inhibitor) }\end{array}$ & Completed & $\begin{array}{c}\text { Tanespimycin in Treating Young Patients With Recurrent } \\
\text { or Refractory Leukemia or Solid Tumors }\end{array}$ \\
\hline
\end{tabular}

TABLe 3: Ongoing clinical trials in DSRCT.

\begin{tabular}{|c|c|c|c|}
\hline Clinical trial (ID); phase & Drugs & Current status & Assigned intervention \\
\hline $\begin{array}{l}\text { NCT01189643; pilot } \\
\text { study }\end{array}$ & CPT-11, TMZ, bevacizumab & $\begin{array}{l}\text { Ongoing } \\
\text { but not } \\
\text { recruiting }\end{array}$ & $\begin{array}{l}\text { Two cycles of the investigational combination } \\
\text { irinotecan, temozolomide, and bevacizumab will be } \\
\text { given followed by conventional chemotherapy with } \\
\text { a modified P6 approach and surgical local control. } \\
\text { Completion of modified P6 chemotherapy will be } \\
\text { followed by a second-look surgery }\end{array}$ \\
\hline NCT01099644; phase I & Biological: ${ }^{131} \mathrm{I}-8 \mathrm{H} 9$ & Recruiting & $\begin{array}{c}\text { Intraperitoneal Radioimmunotherapy With }{ }^{131} \mathrm{I}-8 \mathrm{H} 9 \\
\text { for Patients With Desmoplastic Small Round Cell } \\
\text { Tumors and Other Solid Tumors Involving the } \\
\text { Peritoneum }\end{array}$ \\
\hline NCT02173093; phase I & $\begin{array}{c}\text { Biological: IL-2 | biological: } \\
\text { GD2Bi-aATC | biological: GM-CSF }\end{array}$ & Recruiting & $\begin{array}{c}\text { Activated T Cells Armed With GD2 Bispecific } \\
\text { Antibody in Children and Young Adults With } \\
\text { Neuroblastoma and Osteosarcoma, DSRCT }\end{array}$ \\
\hline NCT02982941; phase I & Drug: enoblituzumab & Recruiting & $\begin{array}{l}\text { Enoblituzumab (MGA271) in Children With B7-H3- } \\
\text { expressing Solid Tumors }\end{array}$ \\
\hline NCT01532687; phase II & Gemcitabine \pm pazopanib & Recruiting & $\begin{array}{c}\text { Gemcitabine Hydrochloride With or Without } \\
\text { Pazopanib Hydrochloride in Treating Patients With } \\
\text { Refractory Soft Tissue Sarcoma }\end{array}$ \\
\hline NCT00089245; phase I & $\begin{array}{l}\text { Radiation: iodine I-131 } \\
\text { monoclonal antibody } 8 \mathrm{H} 9\end{array}$ & Recruiting & $\begin{array}{l}\text { Radiolabeled Monoclonal Antibody Therapy in } \\
\text { Treating Patients with Refractory, Recurrent, or } \\
\text { Advanced CNS or Leptomeningeal Cancer/Sarcomas }\end{array}$ \\
\hline
\end{tabular}

sarcoma (NCT01189643). Similar to many general sarcoma studies, DSRCT is not represented in this study because of the limited number of patients with this disease.

\section{Conclusion}

Because of the rarity of DSRCT, limited data are available regarding the impact of various treatment modalities on survival. Aggressive surgery, radiotherapy, and chemotherapy have all been used to control DSRCT. Unfortunately, durable responses are limited, and the prognosis for patients with DSRCT remains poor [1]. The largest available singleinstitution study of 66 patients with DSRCT reported a 3-year and 5-year overall survival rate of $44 \%$ and $15 \%$, respectively. Use of a combined surgery and a Ewing-based chemotherapy regimen of vincristine, doxorubicin, and cyclophosphamide (VAC) and ifosfamide + etoposide (IE) in various combinations achieves a maximal tumor debulking and is associated with improved overall survival relative to other chemotherapy regimens. Greater than 90\% tumor 
resection was highly significant in prolonging overall survival compared to lesser resections [56]. The impact of optimal debulking was also confirmed in these studies [7, 29].

High-dose chemotherapy, radiotherapy to high-risk sites, and myeloablative chemotherapy with stem cell rescue have been described in selected cases [55]. Some investigators have described the use of cytoreduction and hyperthermic intraperitoneal chemotherapy using cisplatin for treatment of carcinomatosis and yttrium microspheres for treatment of liver metastasis from DSRCT [7]. Consolidative IMRT after debulking and/or HIPEC although used can lead to suboptimal outcomes secondary to GI and hematological toxicities and inferior DFS [96, 97]. Based upon the available data, the treatment strategy currently associated with the best overall survival includes optimal resection of $\geq 90 \%$ of the tumor and high-dose chemotherapy regimens. Given the significant tumor response seen in many patients following systemic chemotherapy, deferring resection until a maximal response to systemic therapy is achieved is currently advocated by some clinical investigators [62].

Little progress has been made in the field of small molecule TKIs for sarcomas since the approval of imatinib for GIST in 2002, and despite the recent FDA approval of the multi-tyrosine kinase inhibitor pazopanib, any direct efficacy for DSRCT is limited and from small retrospective studies. Rather than pursuing different chemotherapy combinations without a solid genomic basis, the field has moved to patient selection based on identifying the optimal combination of targeted therapy, chemotherapy based on chemotherapy sensitivity studies and possibly for high mutational load patient checkpoint inhibitors, or immunotherapy using a tumor signature to determine an approach so as to improve outcomes in clinically applicable ways.

A collaborative effort to include DSRCTs in clinical trials with targeted agents is crucial to determine if there truly is a clinical benefit from this novel treatment option. Recently concluded trials are eagerly awaiting to provide insight into these questions (Table 2) to show a hitherto unsurpassed survival benefit of 26.5 months in SRS with the drug olaratumab and have prompted an accelerated FDA approval in October 2016.

It is unlikely that combinational chemotherapy will significantly improve outcomes in DSRCT. Surgery should remain the cornerstone of treatment. Extended genome sequencing and immunotherapy are being assessed in future clinical trials (Table 3), and it remains to be determined what the role will be in the future for many of the emerging agents.

\section{Conflicts of Interest}

Joanne Xiu is employed by Caris Life Sciences, Phoenix, AZ. The other authors have no conflicts of interest.

\section{References}

[1] C. Honore, K. Amroun, L. Vilcot et al., "Abdominal desmoplastic small round cell tumor: multimodal treatment combining chemotherapy, surgery, and radiotherapy is the best option," Annals of Surgical Oncology, vol. 22, no. 4, pp. 1073-1079, 2015.

[2] A. Dufresne, P. Cassier, L. Couraud et al., "Desmoplastic small round cell tumor: current management and recent findings," Sarcoma, vol. 2012, Article ID 714986, 5 pages, 2012.

[3] W. L. Gerald and J. Rosai, "Case 2 desmoplastic small cell tumor with divergent differentiation," Pediatric Pathology, vol. 9, no. 2, pp. 177-183, 1989.

[4] W. L. Gerald and J. Rosai, "Desmoplastic small cell tumor with multi-phenotypic differentiation," Zentralblatt für Pathologie, vol. 139, no. 2, pp. 141-151, 1993.

[5] M. E. Lae, P. C. Roche, L. Jin, R. V. Lloyd, and A. G. Nascimento, "Desmoplastic small round cell tumor: a clinicopathologic, immunohistochemical, and molecular study of 32 tumors," American Journal of Surgical Pathology, vol. 26, no. 7, pp. 823-835, 2002.

[6] R. E. Schwarz, W. L. Gerald, B. H. Kushner, D. G. Coit, M. F. Brennan, and M. P. La Quaglia, "Desmoplastic small round cell tumors: prognostic indicators and results of surgical management," Annals of Surgical Oncology, vol. 5, no. 5, pp. 416-422, 1998.

[7] A. Hayes-Jordan and P. M. Anderson, "The diagnosis and management of desmoplastic small round cell tumor: a review," Current Opinion in Oncology, vol. 23, no. 4, pp. 385-389, 2011.

[8] E. A. Albano and J. Kanter, "Images in clinical medicine. Sister Mary Joseph's nodule," New England Journal of Medicine, vol. 352, no. 18, p. 1913, 2005.

[9] W. L. Gerald, H. K. Miller, H. Battifora, M. Miettinen, E. G. Silva, and J. Rosai, "Intra-abdominal desmoplastic small round-cell tumor. Report of 19 cases of a distinctive type of high-grade polyphenotypic malignancy affecting young individuals," American Journal of Surgical Pathology, vol. 15, no. 6, pp. 499-513, 1991.

[10] C. R. Antonescu, W. L. Gerald, M. S. Magid, and M. Ladanyi, "Molecular variants of the EWS-WT1 gene fusion in desmoplastic small round cell tumor," Diagnostic Molecular Pathology, vol. 7, no. 1, pp. 24-28, 1998.

[11] W. L. Gerald, J. Rosai, and M. Ladanyi, "Characterization of the genomic breakpoint and chimeric transcripts in the EWSWT1 gene fusion of desmoplastic small round cell tumor," Proceedings of the National Academy of Sciences of the United States of America, vol. 92, no. 4, pp. 1028-1032, 1995.

[12] J. Liu, M. M. Nau, J. C. Yeh, C. J. Allegra, E. Chu, and J. J. Wright, "Molecular heterogeneity and function of EWSWT1 fusion transcripts in desmoplastic small round cell tumors," Clinical Cancer Research, vol. 6, no. 9, pp. 3522$3529,2000$.

[13] S. B. Lee, K. A. Kolquist, K. Nichols et al., "The EWS-WT1 translocation product induces PDGFA in desmoplastic small round-cell tumour," Nature Genetics, vol. 17, no. 3, pp. 309313, 1997.

[14] B. S. Worley, L. T. van den Broeke, T. J. Goletz et al., “Antigenicity of fusion proteins from sarcoma-associated chromosomal translocations," Cancer Research, vol. 61, no. 18, pp. 6868-6875, 2001.

[15] J. Chen, Z. Wu, B. Sun et al., "Intra-abdominal desmoplastic small round cell tumors: CT and FDG-PET/CT findings with histopathological association," Oncology Letters, vol. 11, no. 5, pp. 3298-3302, 2016.

[16] R. Thomas, G. Rajeswaran, K. Thway, C. Benson, K. Shahabuddin, and E. Moskovic, "Desmoplastic small round cell tumour: the radiological, pathological and clinical features," Insights into Imaging, vol. 4, no. 1, pp. 111-118, 2013. 
[17] B. Kis, K. N. O’Regan, A. Agoston, O. Javery, J. Jagannathan, and N. H. Ramaiya, "Imaging of desmoplastic small round cell tumour in adults," British Journal of Radiology, vol. 85, no. 1010, pp. 187-192, 2012.

[18] M. Chouli, J. Viala, C. Dromain, K. Fizazi, P. Duvillard, and D. Vanel, "Intra-abdominal desmoplastic small round cell tumors: CT findings and clinicopathological correlations in 13 cases," European Journal of Radiology, vol. 54, no. 3, pp. 438-442, 2005.

[19] R. A. Vicens, M. Patnana, O. Le et al., "Multimodality imaging of common and uncommon peritoneal diseases: a review for radiologists," Abdominal Imaging, vol. 40, no. 2, pp. 436-456, 2015.

[20] T. Volker, T. Denecke, I. Steffen et al., "Positron emission tomography for staging of pediatric sarcoma patients: results of a prospective multicenter trial," Journal of Clinical Oncology, vol. 25, no. 34, pp. 5435-5441, 2007.

[21] A. Ostermeier, M. B. McCarville, F. Navid, S. E. Snyder, and B. L. Shulkin, "FDG PET/CT imaging of desmoplastic small round cell tumor: findings at staging, during treatment and at follow up," Pediatric Radiology, vol. 45, no. 9, pp. 1308-1315, 2015.

[22] V. C. Arora, A. P. Price, S. Fleming et al., "Characteristic imaging features of desmoplastic small round cell tumour," Pediatric Radiology, vol. 43, no. 1, pp. 93-102, 2013.

[23] N. P. Caraway, C. V. Fanning, R. J. Amato, N. G. Ordóñez, and R. L. Katz, "Fine-needle aspiration of intra-abdominal desmoplastic small cell tumor," Diagnostic Cytopathology, vol. 9, no. 4, pp. 465-470, 1993.

[24] J. Klijanienko, P. Colin, J. Couturier et al., "Fine-needle aspiration in desmoplastic small round cell tumor: a report of 10 new tumors in 8 patients with clinicopathological and molecular correlations with review of the literature," Cancer Cytopathology, vol. 122, no. 5, pp. 386-393, 2014.

[25] J. P. Crapanzano, M. Cardillo, O. Lin, and M. F. Zakowski, "Cytology of desmoplastic small round cell tumor," Cancer, vol. 96, no. 1, pp. 21-31, 2002.

[26] Z. Pohar-Marinsek, "Difficulties in diagnosing small round cell tumours of childhood from fine needle aspiration cytology samples," Cytopathology, vol. 19, no. 2, pp. 67-79, 2008.

[27] U. Gautam, R. Srinivasan, A. Rajwanshi, D. Bansal, and R. K. Marwaha, "Comparative evaluation of flow-cytometric immunophenotyping and immunocytochemistry in the categorization of malignant small round cell tumors in fineneedle aspiration cytologic specimens," Cancer, vol. 114, no. 6, pp. 494-503, 2008.

[28] R. L. Harmon and P. H. Sugarbaker, "Prognostic indicators in peritoneal carcinomatosis from gastrointestinal cancer," International Seminars in Surgical Oncology, vol. 2, no. 1, p. 3, 2005.

[29] A. Hayes-Jordan, H. Green, N. Fitzgerald, L. Xiao, and P. Anderson, "Novel treatment for desmoplastic small round cell tumor: hyperthermic intraperitoneal perfusion," Journal of Pediatric Surgery, vol. 45, no. 5, pp. 1000-1006, 2010.

[30] S. M. Schuetze, "Utility of positron emission tomography in sarcomas," Current Opinion in Oncology, vol. 18, no. 4, pp. 369-373, 2006.

[31] A. W. Rachfal, M. H. Luquette, and D. R. Brigstock, "Expression of connective tissue growth factor (CCN2) in desmoplastic small round cell tumour," Journal of Clinical Pathology, vol. 57, no. 4, pp. 422-425, 2004.

[32] V. Scharnhorst, A. J. van der Eb, and A. G. Jochemsen, "WT1 proteins: functions in growth and differentiation," Gene, vol. 273, no. 2, pp. 141-161, 2001.
[33] J. C. Wong, S. B. Lee, M. D. Bell et al., "Induction of the interleukin-2/15 receptor beta-chain by the EWS-WT1 translocation product," Oncogene, vol. 21, no. 13, pp. 20092019, 2002.

[34] E. Ito, R. Honma, J. Imai et al., "A tetraspanin-family protein, T-cell acute lymphoblastic leukemia-associated antigen 1 , is induced by the Ewing's sarcoma-Wilms' tumor 1 fusion protein of desmoplastic small round-cell tumor," American Journal of Pathology, vol. 163, no. 6, pp. 2165-2172, 2003.

[35] T. A. Natoli, J. A. Alberta, A. Bortvin et al., "Wt1 functions in the development of germ cells in addition to somatic cell lineages of the testis," Developmental Biology, vol. 268, no. 2, pp. 429-440, 2004.

[36] J. F. Armstrong, K. Pritchard-Jones, W. A. Bickmore, N. D. Hastie, and J. B. Bard, "The expression of the Wilms' tumour gene, WT1, in the developing mammalian embryo," Mechanisms of Development, vol. 40, no. 1-2, pp. 85-97, 1993.

[37] A. K. Charles, S. Mall, J. Watson, and P. J. Berry, "Expression of the Wilms' tumour gene WT1 in the developing human and in paediatric renal tumours: an immunohistochemical study," Molecular Pathology, vol. 50, no. 3, pp. 138-144, 1997.

[38] A. J. Murphy, K. Bishop, C. Pereira et al., "A new molecular variant of desmoplastic small round cell tumor: significance of WT1 immunostaining in this entity," Human Pathology, vol. 39, no. 12, pp. 1763-1770, 2008.

[39] P. Bandopadhayay, A. M. Jabbour, C. Riffkin et al., "The oncogenic properties of EWS/WT1 of desmoplastic small round cell tumors are unmasked by loss of p53 in murine embryonic fibroblasts," BMC Cancer, vol. 13, no. 1, p. 585, 2013.

[40] A. A. Sandberg and J. A. Bridge, "Updates on the cytogenetics and molecular genetics of bone and soft tissue tumors. desmoplastic small round-cell tumors," Cancer Genetics and Cytogenetics, vol. 138, no. 1, pp. 1-10, 2002.

[41] S. Movva, W. Wen, W. Chen et al., "Multi-platform profiling of over 2000 sarcomas: identification of biomarkers and novel therapeutic targets," Oncotarget, vol. 6, no. 14, pp. 1223412247, 2015.

[42] P. J. Zhang, J. R. Goldblum, B. R. Pawel, C. Fisher, T. L. Pasha, and F. G. Barr, "Immunophenotype of desmoplastic small round cell tumors as detected in cases with EWS-WT1 gene fusion product," Modern Pathology, vol. 16, no. 3, pp. 229235, 2003.

[43] J. Xiu, A. Bulbul, and S. Rashad, "Potential therapeutic genomic alterations in desmoplastic small round blue cell tumor," Journal of Clinical Oncology, vol. 35, no. 15, p. 11066, 2017.

[44] S. Hirota, K. Isozaki, Y. Moriyama et al., "Gain-of-function mutations of c-kit in human gastrointestinal stromal tumors," Science, vol. 279, no. 5350, pp. 577-580, 1998.

[45] J. R. Kim, Y. J. Moon, K. S. Kwon et al., “Tumor infiltrating PD1-positive lymphocytes and the expression of PD-L1 predict poor prognosis of soft tissue sarcomas," PLoS One, vol. 8, no. 12, p. e82870, 2013.

[46] L. Paoluzzi, M. V. Ghesani, A. Cacavio, A. Rapkiewicz, and G. Rosen, "Anti-PD1 therapy with nivolumab in sarcoma," Journal of Clinical Oncology, vol. 34, no. 15, p. 11047, 2016.

[47] M. A. Burgess, J. Crowley, D. K. Reinke et al., "SARC 028: a phase II study of the anti-PD1 antibody pembrolizumab (P) in patients (Pts) with advanced sarcomas," Journal of Clinical Oncology, vol. 33, no. 15, p. TPS10578, 2015.

[48] B. Timmermann, M. Kerick, C. Roehr et al., "Somatic mutation profiles of MSI and MSS colorectal cancer identified by whole exome next generation sequencing and bioinformatics analysis," PLoS One, vol. 5, no. 12, p. e15661, 2010. 
[49] D. T. Le, J. N. Uram, H. Wang et al., "PD-1 blockade in tumors with mismatch-repair deficiency," New England Journal of Medicine, vol. 372, no. 26, pp. 2509-2520, 2015.

[50] R. J. Motzer, B. Escudier, D. F. McDermott et al., "Nivolumab versus everolimus in advanced renal-cell carcinoma," New England Journal of Medicine, vol. 373, no. 19, pp. 1803-1813, 2015.

[51] M. Burgess and H. Tawbi, "Immunotherapeutic approaches to sarcoma," Current Treatment Options in Oncology, vol. 16, no. 6, p. 26, 2015.

[52] S. Champiat, C. Ferté, S. Lebel-Binay, A. Eggermont, and J. C. Soria, "Exomics and immunogenics: bridging mutational load and immune checkpoints efficacy," Oncoimmunology, vol. 3, no. 1, p. e27817, 2014.

[53] M. Mellado-Lagarde, S. M. Federico, C. Tinkle, A. Shelat, and E. Stewart, "PARP inhibitor combination therapy in desmoplastic small round cell tumors," Journal of Clinical Oncology, vol. 35, no. 15, p. e23212, 2017.

[54] A. Hayes-Jordan, H. L. Green, H. Lin et al., "Complete cytoreduction and HIPEC improves survival in desmoplastic small round cell tumor," Annals of Surgical Oncology, vol. 21, no. 1, pp. 220-224, 2014.

[55] B. H. Kushner, M. P. LaQuaglia, N. Wollner et al., "Desmoplastic small round-cell tumor: prolonged progressionfree survival with aggressive multimodality therapy," Journal of Clinical Oncology, vol. 14, no. 5, pp. 1526-1531, 1996.

[56] D. R. Lal, W. T. Su, S. L. Wolden, K. C. Loh, S. Modak, and M. P. La Quaglia, "Results of multimodal treatment for desmoplastic small round cell tumors," Journal of Pediatric Surgery, vol. 40, no. 1, pp. 251-255, 2005.

[57] K. A. Goodman, S. L. Wolden, M. P. La Quaglia, and B. H. Kushner, "Whole abdominopelvic radiotherapy for desmoplastic small round-cell tumor," International Journal of Radiation Oncology, Biology, Physics, vol. 54, no. 1, pp. 170-176, 2002.

[58] C. C. Pinnix, H. P. Fontanilla, A. Hayes-Jordan et al., "Whole abdominopelvic intensity-modulated radiation therapy for desmoplastic small round cell tumor after surgery," International Journal of Radiation Oncology, Biology, Physics, vol. 83, no. 1, pp. 317-326, 2012.

[59] V. Subbiah, R. Murthy, and P. M. Anderson, "[ $\left.{ }^{90} Y\right] Y$ ttrium microspheres radioembolotherapy in desmoplastic small round cell tumor hepatic metastases," Journal of Clinical Oncology, vol. 29, no. 11, pp. e292-e294, 2011.

[60] M. Mazuryk, A. H. Paterson, W. Temple, K. Arthur, T. Crabtree, and D. A. Stewart, "Benefit of aggressive multimodality therapy with autologous stem cell support for intra-abdominal desmoplastic small round cell tumor," Bone Marrow Transplantation, vol. 21, no. 9, pp. 961-963, 1998.

[61] G. Bisogno, A. Ferrari, A. Rosolen et al., "Sequential intensified chemotherapy with stem cell rescue for children and adolescents with desmoplastic small round-cell tumor," Bone Marrow Transplantation, vol. 45, no. 5, pp. 907-911, 2010.

[62] A. Hayes-Jordan, M. P. LaQuaglia, and S. Modak, "Management of desmoplastic small round cell tumor," Seminars in Pediatric Surgery, vol. 25, no. 5, pp. 299-304, 2016.

[63] F. Farhat, S. Culine, C. Lhomme et al., "Desmoplastic small round cell tumors: results of a four-drug chemotherapy regimen in five adult patients," Cancer, vol. 77, no. 7, pp. 1363-1366, 1996.

[64] D. A. Casey, L. H. Wexler, M. S. Merchant et al., "Irinotecan and temozolomide for Ewing sarcoma: the Memorial SloanKettering experience," Pediatric Blood \& Cancer, vol. 53, no. 6, pp. 1029-1034, 2009.
[65] J. Grill, B. Geoerger, L. Gesner et al., "Phase II study of irinotecan in combination with temozolomide (TEMIRI) in children with recurrent or refractory medulloblastoma: a joint ITCC and SIOPE brain tumor study," Neuro-Oncology, vol. 15, no. 9, pp. 1236-1243, 2013.

[66] B. H. Kushner, P. A. Meyers, W. L. Gerald et al., "Very-highdose short-term chemotherapy for poor-risk peripheral primitive neuroectodermal tumors, including Ewing's sarcoma, in children and young adults," Journal of Clinical Oncology, vol. 13, no. 11, pp. 2796-2804, 1995.

[67] B. H. Kushner, M. P. LaQuaglia, M. A. Bonilla et al., "Highly effective induction therapy for stage 4 neuroblastoma in children over 1 year of age," Journal of Clinical Oncology, vol. 12, no. 12, pp. 2607-2613, 1994.

[68] T. Watanabe, S. Miyamoto, K. Kitagori et al., "A case of longterm survival of metastatic desmoplastic small round cell tumor treated with multimodal therapy," Oncology Letters, vol. 3, no. 1, pp. 30-34, 2012.

[69] J. E. Visvader and G. J. Lindeman, "Cancer stem cells in solid tumours: accumulating evidence and unresolved questions," Nature Reviews Cancer, vol. 8, no. 10, pp. 755-768, 2008.

[70] M. L. Suva, N. Riggi, J. C. Stehle et al., "Identification of cancer stem cells in Ewing's sarcoma," Cancer Research, vol. 69, no. 5, pp. 1776-1781, 2009.

[71] H. E. Grier, M. D. Krailo, N. J. Tarbell et al., "Addition of ifosfamide and etoposide to standard chemotherapy for Ewing's sarcoma and primitive neuroectodermal tumor of bone," New England Journal of Medicine, vol. 348, no. 8, pp. 694-701, 2009.

[72] H. Werner, G. Idelman, M. Rubinstein, P. Pattee, S. R. Nagalla, and C. T. Roberts Jr., "A novel EWS-WT1 gene fusion product in desmoplastic small round cell tumor is a potent transactivator of the insulin-like growth factor-I receptor (IGF-IR) gene," Cancer Letters, vol. 247, no. 1, pp. 84-90, 2007.

[73] D. Aguilera, A. Hayes-Jordan, P. Anderson, S. Woo, M. Pearson, and H. Green, "Outpatient and home chemotherapy with novel local control strategies in desmoplastic small round cell tumor," Sarcoma, vol. 2008, Article ID 261589, 9 pages, 2008.

[74] O. M. Tirado, S. Mateo-Lozano, and V. Notario, "Rapamycin induces apoptosis of JN-DSRCT-1 cells by increasing the Bax : $\mathrm{Bcl}-\mathrm{xL}$ ratio through concurrent mechanisms dependent and independent of its mTOR inhibitory activity," Oncogene, vol. 24, no. 20, pp. 3348-3357, 2005.

[75] A. M. Thijs, W. T. van der Graaf, and C. M. van Herpen, "Temsirolimus for metastatic desmoplastic small round cell tumor," Pediatric Blood \& Cancer, vol. 55, no. 7, pp. 1431-1432, 2010.

[76] A. Dimitrakopoulou-Strauss, P. Hohenberger, P. Strobel, A. Marx, and L. G. Strauss, "A recent application of fluoro-18deoxyglucose positron emission tomography, treatment monitoring with a mammalian target of rapamycin inhibitor: an example of a patient with a desmoplastic small round cell tumor," Hellenic Journal of Nuclear Medicine, vol. 10, no. 2, pp. 77-79, 2007.

[77] A. M. Frezza, C. Benson, I. R. Judson et al., "Pazopanib in advanced desmoplastic small round cell tumours: a multiinstitutional experience," Clinical Sarcoma Research, vol. 4, p. 7, 2014.

[78] W. D. Tap, R. L. Jones, B. A. Van Tine et al., "Olaratumab and doxorubicin versus doxorubicin alone for treatment of softtissue sarcoma: an open-label phase $1 \mathrm{~b}$ and randomised phase 2 trial," Lancet, vol. 388, no. 10043, pp. 488-497, 2016.

[79] W. T. van der Graaf, J. Y. Blay, S. P. Chawla et al., "Pazopanib for metastatic soft-tissue sarcoma (PALETTE): a randomised, 
double-blind, placebo-controlled phase 3 trial," Lancet, vol. 379, no. 9829, pp. 1879-1886, 2012.

[80] P. Schoffski, S. Chawla, R. G. Maki et al., "Eribulin versus dacarbazine in previously treated patients with advanced liposarcoma or leiomyosarcoma: a randomised, open-label, multicentre, phase 3 trial," Lancet, vol. 387, no. 10028, pp. 1629-1637, 2016.

[81] G. D. Demetri, M. von Mehren, R. L. Jones et al., "Efficacy and safety of trabectedin or dacarbazine for metastatic liposarcoma or leiomyosarcoma after failure of conventional chemotherapy: results of a phase III randomized multicenter clinical trial," Journal of Clinical Oncology, vol. 34, no. 8, pp. 786-793, 2016.

[82] P. Schoffski, I. L. Ray-Coquard, A. Cioffi et al., "Activity of eribulin mesylate in patients with soft-tissue sarcoma: a phase 2 study in four independent histological subtypes," Lancet Oncology, vol. 12, no. 11, pp. 1045-1052, 2011.

[83] R. G. Maki, "Eribulin in soft-tissue sarcomas," Lancet Oncology, vol. 12, no. 11, pp. 988-989, 2011.

[84] E. K. Rowinsky and R. C. Donehower, "The clinical pharmacology and use of antimicrotubule agents in cancer chemotherapeutics," Pharmacology \& Therapeutics, vol. 52, no. 1, pp. 35-84, 1991.

[85] M. L. Hensley, R. Maki, E. Venkatraman et al., "Gemcitabine and docetaxel in patients with unresectable leiomyosarcoma: results of a phase II trial," Journal of Clinical Oncology, vol. 20, no. 12, pp. 2824-2831, 2002.

[86] K. M. Leu, L. J. Ostruszka, D. Shewach et al., "Laboratory and clinical evidence of synergistic cytotoxicity of sequential treatment with gemcitabine followed by docetaxel in the treatment of sarcoma," Journal of Clinical Oncology, vol. 22, no. 9, pp. 1706-1712, 2004.

[87] J. O. Bay, I. Ray-Coquard, J. Fayette et al., "Docetaxel and gemcitabine combination in 133 advanced soft-tissue sarcomas: a retrospective analysis," International Journal of Cancer, vol. 119, no. 3, pp. 706-711, 2006.

[88] R. T. Kurmasheva, L. Dudkin, C. Billups, L. V. Debelenko, C. L. Morton, and P. J. Houghton, "The insulin-like growth factor-1 receptor-targeting antibody, CP-751,871, suppresses tumor-derived VEGF and synergizes with rapamycin in models of childhood sarcoma," Cancer Research, vol. 69, no. 19, pp. 7662-7671, 2009.

[89] A. Naing, P. LoRusso, S. Fu et al., "Insulin growth factorreceptor (IGF-1R) antibody cixutumumab combined with the mTOR inhibitor temsirolimus in patients with refractory Ewing's sarcoma family tumors," Clinical Cancer Research, vol. 18, no. 9, pp. 2625-2631, 2012.

[90] S. P. D'Angelo, A. N. Shoushtari, N. P. Agaram et al., "PD-L1 expression and immune infiltrates in sarcoma," Journal of Clinical Oncology, vol. 32, no. 15, p. 10522, 2014.

[91] S. Modak, W. Gerald, and N. K. Cheung, "Disialoganglioside GD2 and a novel tumor antigen: potential targets for immunotherapy of desmoplastic small round cell tumor," Medical and Pediatric Oncology, vol. 39, no. 6, pp. 547-551, 2002.

[92] W. D. Tap, G. Demetri, P. Barnette et al., "Phase II study of Ganitumab, a fully human anti-type-1 insulin-like growth factor receptor antibody, in patients with metastatic Ewing family tumors or desmoplastic small round cell tumors," Journal of Clinical Oncology, vol. 30, no. 15, pp. 1849-1856, 2016.

[93] S. P. D’Angelo, A. N. Shoushtari, N. P. Agaram et al., "Prevalence of tumor infiltrating lymphocytes and PD-L1 expression in the soft tissue sarcoma microenvironment," Human Pathology, vol. 46, no. 3, pp. 357-365, 2015.
[94] H. D. Magnan, T. Chou, M. P. LaQuaglia, W. Gerald, M. Ladanyi, and M. S. Merchant, "Elevated expression of VEGFR-2 and VEGFA in desmoplastic small round cell tumor (DSRCT) and activity of bevacizumab and irinotecan in a xenograft model of DSRCT," Journal of Clinical Oncology, vol. 27, no. 15, p. 20, 2016.

[95] H. D. Magnan, A. Price, A. J. Chou et al., "A pilot trial of irinotecan, temozolomide and bevacizumab (ITB) for treatment of newly diagnosed patients with desmoplastic small round cell tumor (DSRCT)," in Proceedings of American Society of Clinical Oncology Annual Meeting Abstracts ASCO'17, Chicago, IL, USA, July 2017.

[96] N. B. Desai, N. F. Stein, M. P. LaQuaglia et al., "Reduced toxicity with intensity modulated radiation therapy (IMRT) for desmoplastic small round cell tumor (DSRCT): an update on the whole abdominopelvic radiation therapy (WAP-RT) experience," International Journal of Radiation Oncology, Biology, Physics, vol. 85, no. 1, pp. e67-e72, 2013.

[97] E. M. Osborne, T. M. Briere, and A. Hayes-Jordan, "Survival and toxicity following sequential multimodality treatment including whole abdominopelvic radiotherapy for patients with desmoplastic small round cell tumor," Radiotherapy and Oncology, vol. 119, no. 1, pp. 40-44, 2017.

[98] H. H. Wong, H. M. Hatcher, C. Benson et al., "Desmoplastic small round cell tumour: characteristics and prognostic factors of 41 patients and review of the literature," Clinical Sarcoma Research, vol. 3, no. 1, p. 14, 2013. 


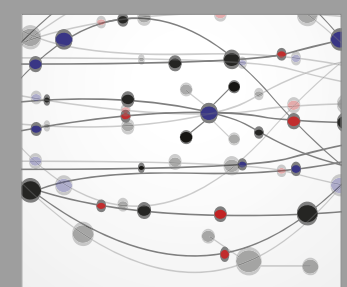

The Scientific World Journal
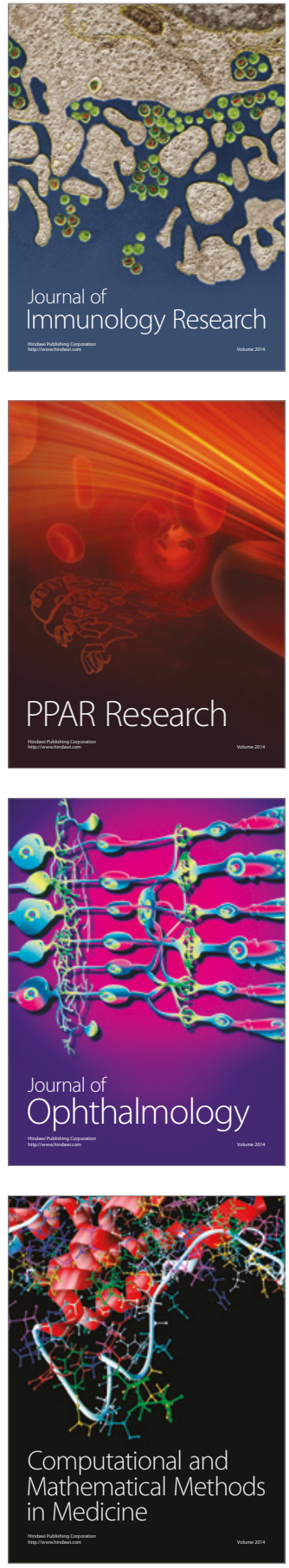

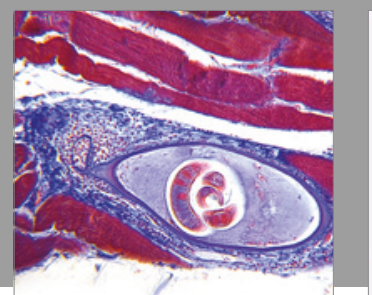

Gastroenterology Research and Practice
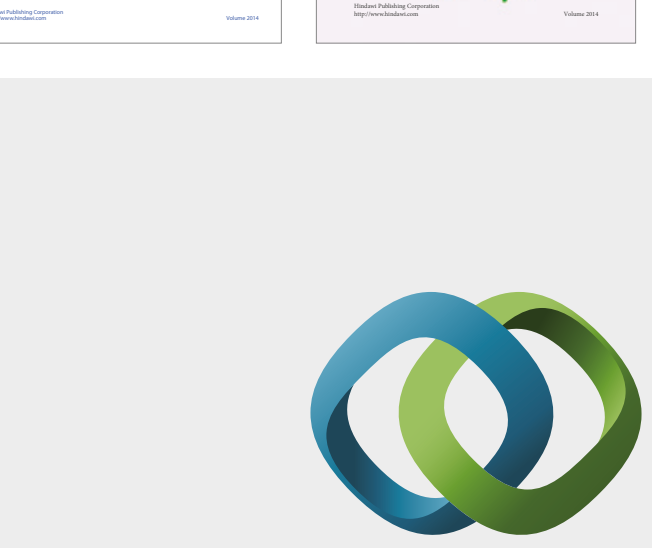

\section{Hindawi}

Submit your manuscripts at

https://www.hindawi.com
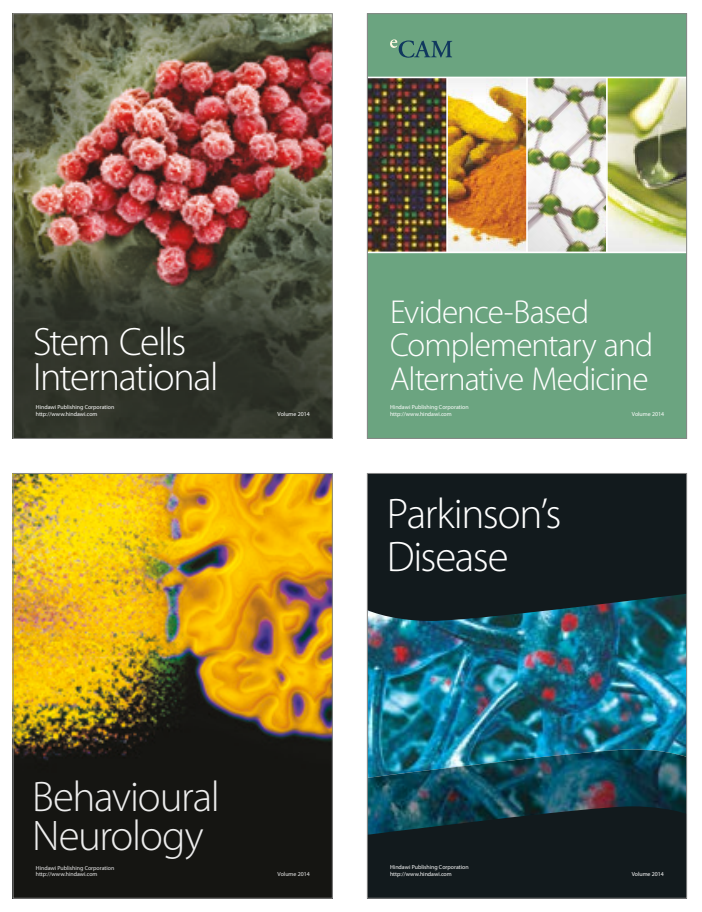
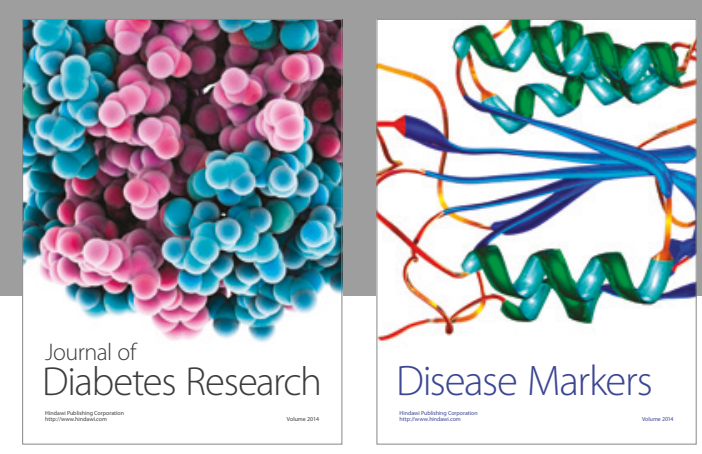

Disease Markers
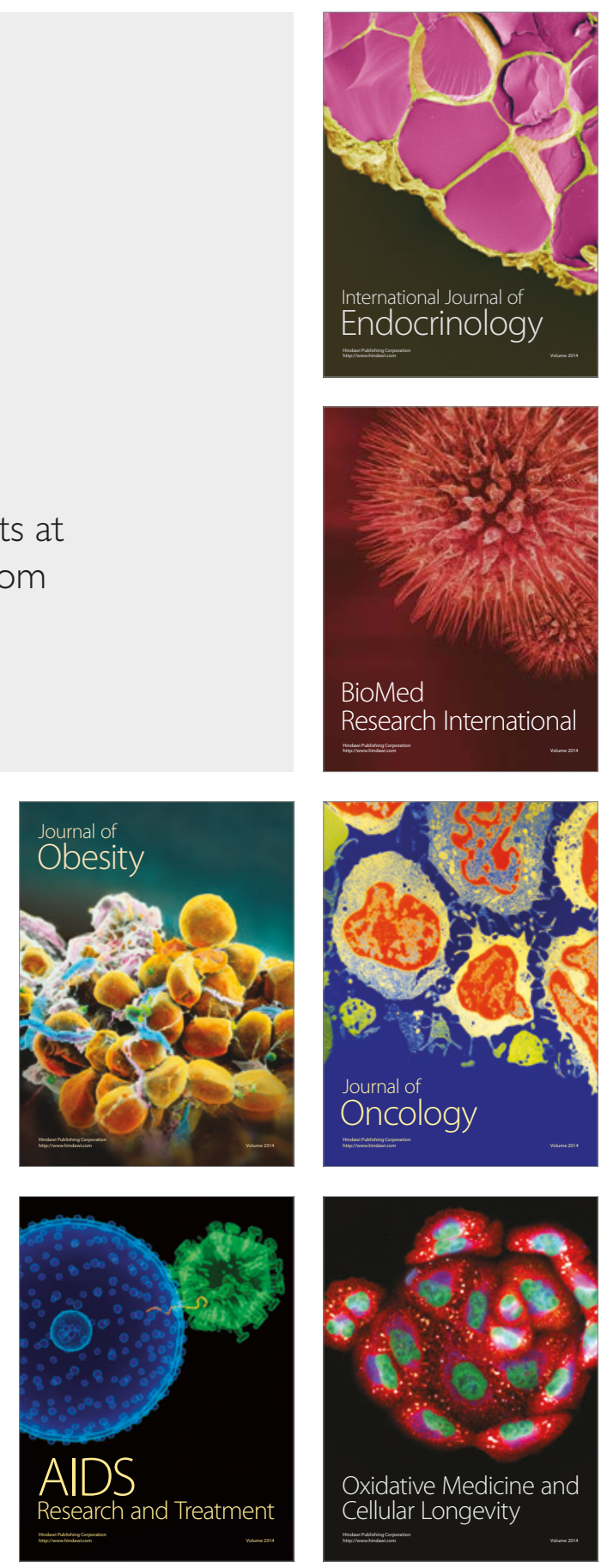